\title{
A Method of Assessing Parameters of Air-Void Structure in Air-Entrained Concretes
}

\author{
Jerzy Wawrzeńczyk and Wioletta Kozak \\ Faculty of Civil Engineering and Architecture, Kielce University of Technology, Kielce 25-314, Poland
}

\begin{abstract}
The air-void size distribution and number of air voids are crucial characteristics of air-entrainment. The standard spacing factor $L$ is based on the Powers model, in which considerable simplifications are assumed. A better solution is provided by the Philleo factor, which determines the percentage content of protected paste located at a distance $S$ from the edge of the nearest air void. Developing the concept put forward by Philleo, a method of determining the volume of protected paste on the basis of images generated from the numerical model of concrete grain structure including layout of aggregate-paste-air, is proposed. It is the ratio of the volume of the paste protected by air voids to the total paste volume. The PPV (protected paste volume) index accounts not only for sizes and number of air voids, but also for the role of aggregate particles in the placement of these pores, which is often disregarded in analyses. The PPV results obtained from image analysis were compared with standard spacing factor $L$ and with the parameter developed by Philleo. The analyses conducted by the authors shows that accounting for aggregate grains in calculations substantially affects the assessment of the quality of the air-pore structure.
\end{abstract}

Key words: Distribution of air pore sizes, distribution of aggregate grain sizes, protected paste area, numerical model of the porosity of the concrete.

\section{Introduction}

Air-entrainment, a basic method of protecting concrete against the destructive action of frost, water and de-icing salts, has been known for over 70 years. According to requirements laid down in PN-EN 206-1 standard [1], at least $4 \%$ of air should be introduced to the concrete mix, but it does not specify any guidelines regarding what the structure of the air voids should be. Unfortunately, not only the volume of air-entrained, but also the parameters of the pore structure, such as the spacing factor $L$, the content of micropores $A_{300}$, the total air content $A$ and the specific surface of air-void system $\alpha$, decide about obtaining frost resistance. The first document in Poland, which specifies the requirements for these parameters, is "Technical Requirements for Concrete Pavements" [2]. According to this document, the frost-resistant concrete has a spacing factor $L$ smaller than $200 \mu \mathrm{m}$ and the content of

Corresponding author: Jerzy Wawrzeńczyk, professor, research fields: concrete technology and freeze-thaw durability. E-mail: zmsjw@tu.kielce.pl. micropores greater than $1.5 \%$. Air-entrainment technology involves introducing a surfactant into the concrete mix. When the components are mixed, the air-entraining agent makes it possible to form and evenly disperse small air bubbles in the concrete. The system of small air voids protects concrete from damage caused by an increase in the volume of freezing water. Appropriate spacing of air voids in hardened cement paste significantly reduces the distance to be travelled by water that is not frozen yet, from a random point inside the hardened cement paste to the nearest air void [3]. To ensure freeze-thaw resistance, it is essential to provide a time-stable system of small air bubbles, which are located close enough to one another, at the lowest possible total air content. In modern concrete technology, simultaneous usage of cement, additives and admixtures often cause problems related to obtaining the time-stable pore system. The effects of air-entrainment may differ due to the action of many factors, including the mix consistency and temperature, mixing time, transport 
time, type of the concrete mix placing and compacting. Substantial air losses occur when the concrete mix is pumped (approximately 1\% 1.5\%), and also vibrated [4]. Air-entrainment can be also dependent on the characteristics of the aggregate grains, especially of sand (roughness, number and shape of grains) [5], which are often unaccounted for. Taking into account a large number of factors that affect the quality of air-entrainment, it may happen that air-entraining agents will not generate the required pore structure. Diamond in Snyder's [6] paper claims that the aggregate presence may, however, substantially affect the spacing of air bubbles. Consequently, the maximum distance, measured along the cement paste, will grow. As a result, the pore spacing factor $L$ is increased, yet the total air content $(A)$ does not change. Therefore, simple measurements of air content cannot provide the basis for assessing the quality of air-entrained concrete porosity. Thus, it is necessary to establish air-entrainment quality control, which involves the microscopy assessment of air-pore structure. The method of determining the parameters of air-pore structure is presented in the standard PN EN 480-11 [7] or ASTM C 457 [8]. The former standard [7] specifies the determination of the pore structure parameters on the basis of the Powers model, which assumes that all bubbles have the same diameter and are distributed in cube corners (Fig. 1). Thus, spacing factor $L$ corresponds to a half of the cube diagonal. The basic parameter that relates the quality of air-entrained
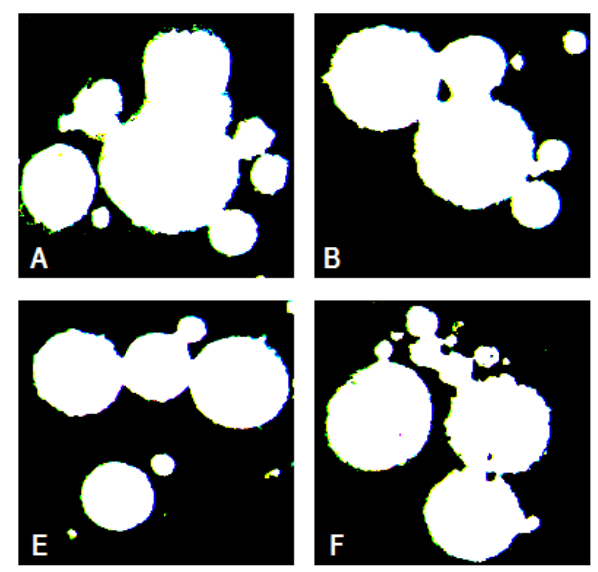

concrete to its freeze-thaw resistance is spacing factor $L$.

The assumptions adopted in the Powers model may, in some cases, make the model incompatible with the real air-void structure in the concrete. Fig. 2 (from A to $\mathrm{H})$ presents exemplary photographs of air pores, which shows that in modern concretes (concretes in which cement, additives and admixtures are used), pores often coalesce to form larger systems, or they can have bizarre shapes. A large number of such interconnected air pores cause a significant departure from the assumptions of the Powers model, and thus increases the inaccuracy of the calculation.

The Powers model do not account for the distribution of air-pore sizes in the concrete. It is therefore necessary to develop a model that will take into account the diversity of pore diameters and pore non-uniform spacing in the cement paste to more accurately describe the actual structure of air bubbles, and thus to better determine concrete freeze-thaw resistance. These problems have been noticed a long

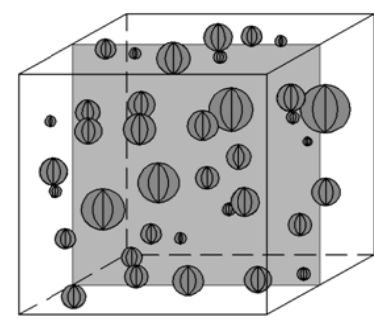

The real model

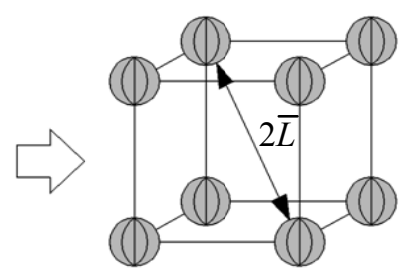

The Powers model
Fig. 1 Difference between the actual air-pore distribution and that assumed in the Powers model [9].
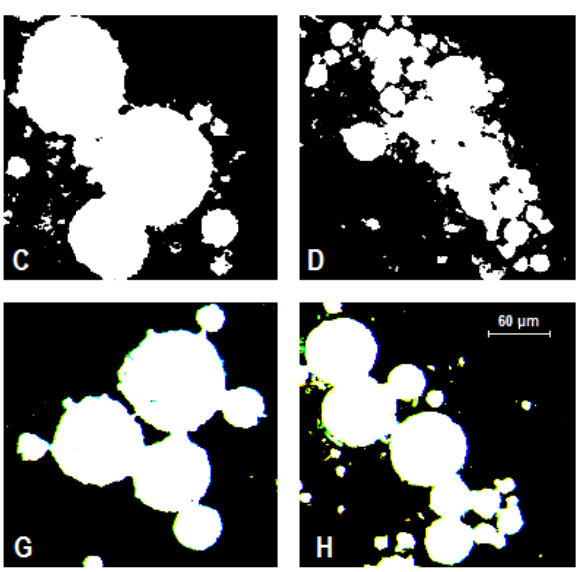

Fig. 2 View of complex pore arrangements in air-entrained concretes. 
time ago and are largely limited to two issues: first, whether the Powers' approach correctly describes the structure of the air voids, and second, whether these parameters properly evaluate the frost resistance. Other ways of describing air-pore structure are sought by researchers, including Philleo [10], Attiogbe [11], Jin et al. [12], Elsen et al. [13], Shanshan et al. [14] and Zalocha and Kasperkiewicz [15]. In accordance with Philleo, each air bubble protects the paste area around it, which has the width of $S$, from the detrimental frost action (Fig. 3).

The air void spacing factor $S^{*}$, proposed by Philleo, is based on the logarithmic distribution. While using the gamma distribution, Attiogbe determined the parameter $F$, which like factor $S^{*}$, gives the volume of the paste potentially protected by air bubbles. The method proposed by Philleo only requires the knowledge of the total volume of air in the paste and the number of voids per unit volume of paste. To determine the number of air voids per unit volume of concrete, Philleo used data from a slight modification of the linear traverse method:

$$
N=\frac{\left(\frac{2}{\pi}\right) \cdot N_{c}}{l \cdot \Delta l}
$$

where:

$N$ is the number of bubbles per unit volume of concrete;

$N_{c}$ is the number of chords per unit length of traverse;

$l$ is midpoint of the smallest size group;

$\Delta l$ is the width of the size group into which chords are classified.

As a practical matter, $N$ should be based on the value of $l$, which produces the highest value for $N$ [10]. Using the formula:

$$
S \cdot N^{1 / 3}=0.62\left[\left(\ln \frac{1}{1-A}+2.303\right)^{1 / 3}-\left(\ln \frac{1}{1-A}\right)^{1 / 3}\right]
$$

where:

$S$ is a distance measured from the edge of air void; $A$ is air content of paste, fraction of air-entrained paste;

ln is natural logarithm.

The $S \cdot N^{1 / 3}$ value is determined. Then, for a given air content $A$ and the calculated value of $S \cdot N^{1 / 3}$, the percentage content of cement paste at a distance of $S$ from the edge of the air gap is read from the nomogram.

The numerical model developed in the present study takes into account the aggregate-paste-air system. On the basis of the results obtained for this model, the PPV (protected paste volume) index is computed and, further, compared with the results produced with the standard method and also in accordance with Philleo method.

\section{Numerical Model of the Porosity of the Concrete}

The investigations aimed to describe the characteristics of the air-entrained concrete structure parameters on the basis of $2 \mathrm{D}$ analysis while taking into account the actual pore distribution. The manner of taking measurements of pore characteristics is presented in Fig. 4.

To perform 2D analysis, it is necessary to have concrete images, which contain four separate phases: aggregate, paste, air and rings of the paste protected by air voids. The structure of real concrete does not show sufficient contrast, consequently, it is difficult to differentiate individual phases. In their investigations, the authors conducted an initial experiment, which involved the development of the model that would make

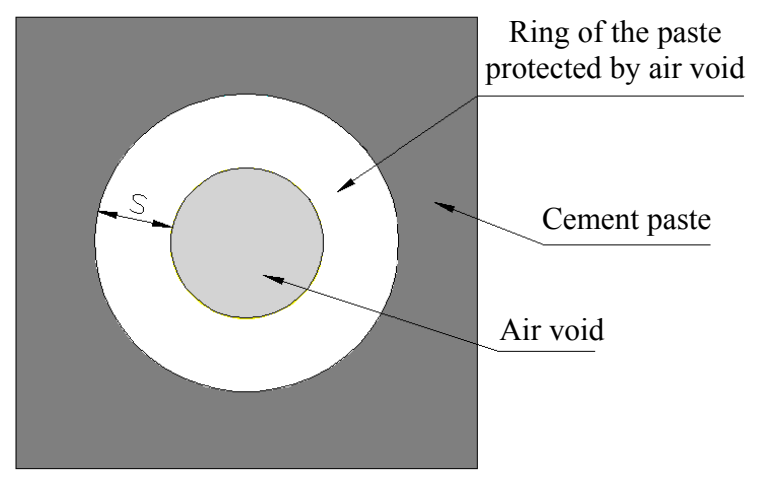

Fig. 3 Philleo factor. 

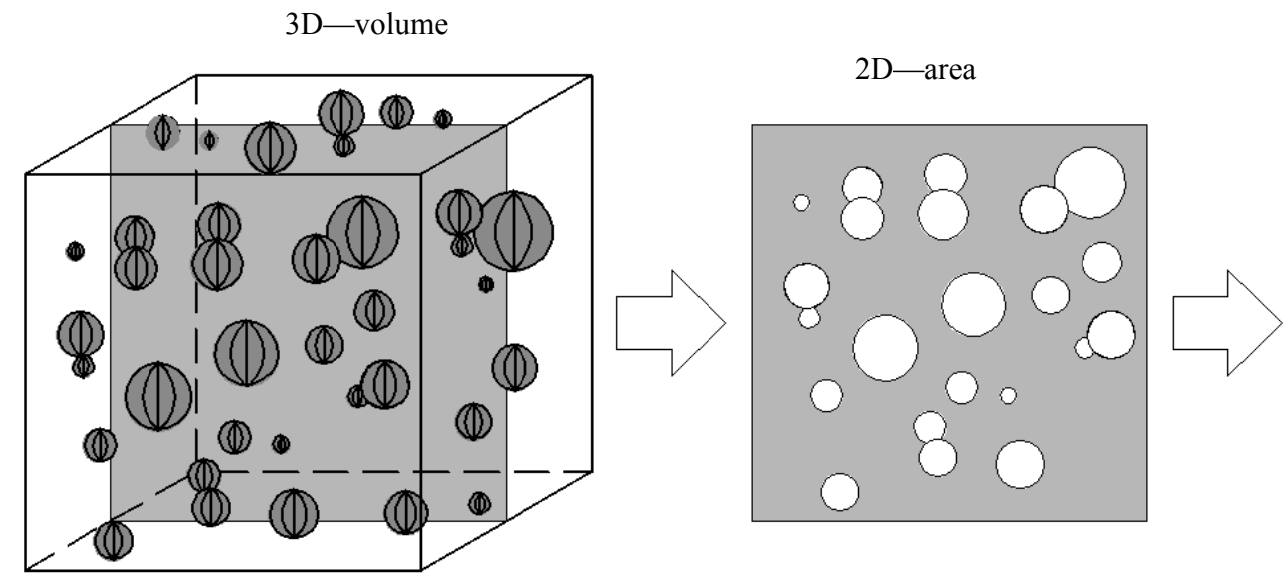

The Powers model

Fig. 4 Measurement of air-pore characteristics on the basis of the 2D analysis.

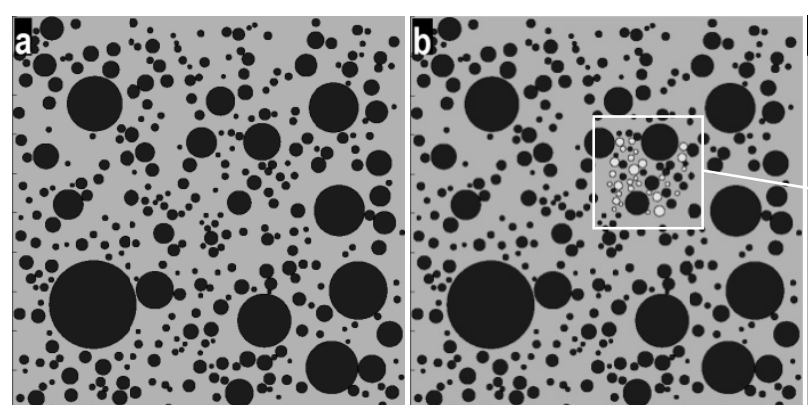

(a) (b)

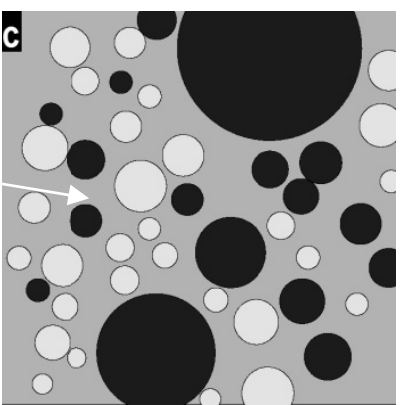

(c)

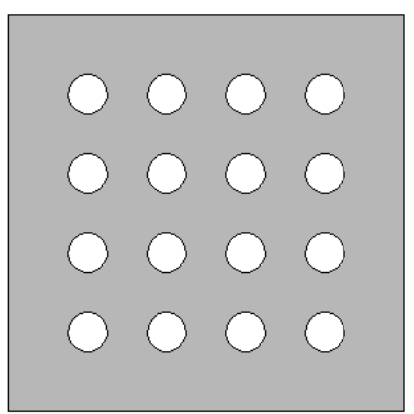

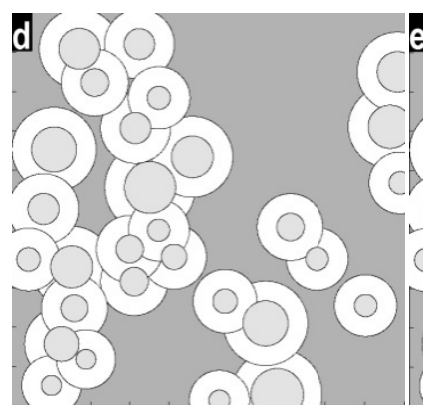

(d)

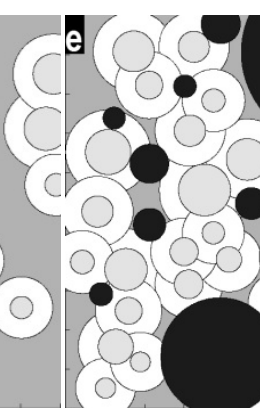

(e)

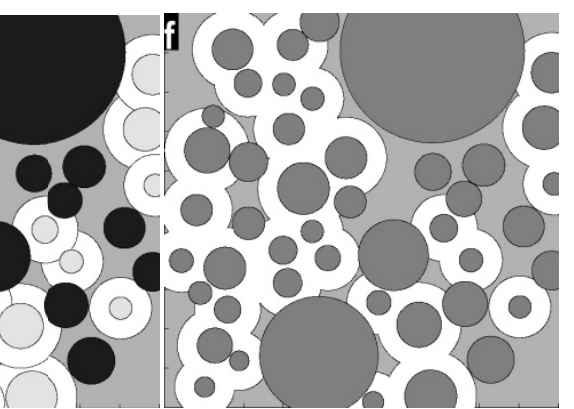

(f)

Fig. 5 Image generation: (a) spacing of aggregate particles in the paste; (b) addition of air voids in the selected area; (c)air and aggregate in the analyzed area; (d) imposing rings of protected paste around air voids; (e) all four phases accounted for; (f) protected paste (white) and unprotected paste (light grey).

it possible to generate a simplified image of the concrete grain structure, in which the four basic phases could be differentiated. This model was developed in MATLAB environment [16]. The method of generating and randomly distributing grain structures has been used for years. Yet, it is applied to concrete fracture mechanics, but not to the analysis of concrete air-pore structure [17-19]. It was assumed that both aggregate particles and air pores are round and they cannot coalesce. The data entered into the program include: percentage content of aggregate, air and paste, the aggregate grading curve, air-pore diameter distribution and the thickness of the surrounding layer $S$. The manner of image generation and making calculations is shown in Fig. 5. First, aggregate grain sizes are generated in accordance with the aggregate grading curve (Fig. 7), then, those are randomly distributed in the paste area of $100 \mathrm{~mm} \times 100 \mathrm{~mm}$ (Fig. 5a, black). In the next step, air pores are randomly distributed (Fig. 5c, light grey) among aggregate grains. 
The pore diameters are generated in accordance with the assumed distribution of pore sizes (Fig. 6). Next, surrounds, $0.200 \mathrm{~mm}$ in thickness, are produced around air bubbles (Fig. 5d, white). Then, air and aggregate in accordance with Fig. $5 \mathrm{c}$ are subtracted from Fig. 5d leaving, in Fig. 5e, the area of protected paste (white) and the paste area, which remains unprotected (dark grey).

The final outcome, namely Fig. 5f, makes it possible to compute the percentage ratio PPV of the protected paste area (white) to the total paste area (white + light grey). The generated image of concrete structure also makes it possible to determine the standard parameters of air-pore structure [7] and the parameter in accordance with Philleo method. The randomness in generating the sizes of air bubbles and aggregate particles, and also their random distribution in the paste results in the fact that the data entered into the program do not differ much from the output data.

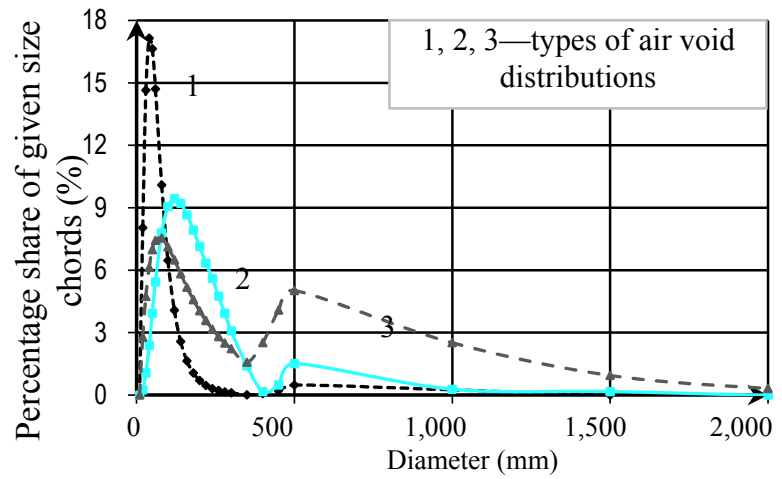

Fig. 6 Types of air-void distributions used in the investigations [20].

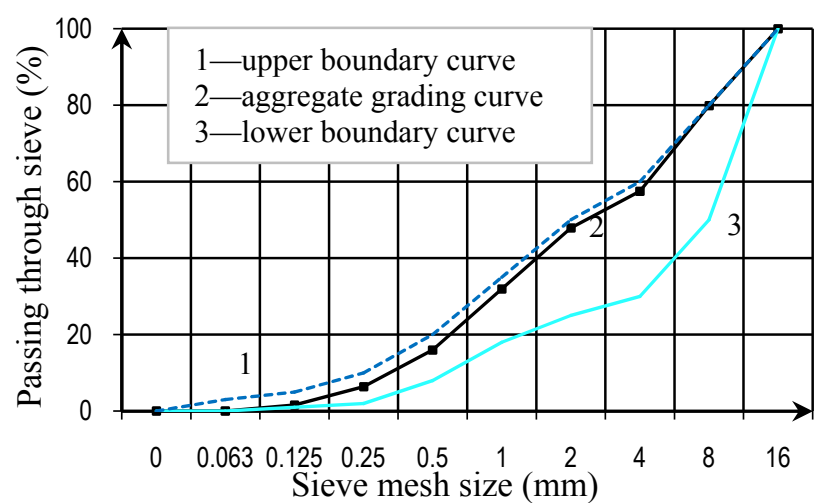

Fig. 7 Aggregate grading curve together with boundary curves used in investigations.
For our model, it was necessary to determine the size distribution of air bubbles. Investigations into the pore structure in air-entrained concretes have been conducted, for many years, at the Optical Microscopy Laboratory of the Construction Technology and Organization Department at the Kielce University of Technology. The analysis of the determination of the parameters of air voids distribution was performed using the Table Curve 2D software ${ }^{1}$. Air-entrained concretes having diversified parameters of porosity structure were investigated. On the basis of analysis of the results of investigations on a few series of concretes, it was found that log-normal distribution is the most suitable tool to describe chord size distribution in the concrete. The analysis confirms that the larger is the number of measured chords, the better is the distribution fit and more precise is the estimation of porosity characteristics. In such cases, using log-normal distribution in computations produces similar results. For concretes having low air content or large pores, a considerable difference is found between results of computations on the raw data and those obtained from the distribution, which produces incongruent results. In such case, it would be advisable to increase a number of tested samples [20].

\section{Results Obtained from Numerical Model and Their Analysis}

The article presents a comparative analysis of air-void structure parameters obtained from the images generated from the numerical model of concrete grain structure including aggregate-paste-air system. These characteristics were obtained by using three methods: the standard one, Philleo's and the authors', for three concrete models with different variants of the air entrainment structure (Fig. 6). All variants have the same aggregate grading curve presented in Fig. 7 and the content of air about $2 \%, 4 \%, 6 \%$ and $8 \%$.

The test results obtained from a single-image are presented in Table 1.

\footnotetext{
${ }^{1}$ Table Curve 2D, SYSTAT.
} 
Table 1 Comparison of results obtained from the numerical model.

\begin{tabular}{|c|c|c|c|c|c|c|c|c|c|c|c|c|c|c|}
\hline \multirow{3}{*}{\multicolumn{3}{|c|}{ Parameter }} & \multicolumn{12}{|c|}{ Concrete model } \\
\hline & & & \multicolumn{4}{|c|}{ With Distribution 1} & \multicolumn{4}{|c|}{ With Distribution 2} & \multicolumn{4}{|c|}{ With Distribution 3} \\
\hline & & & $\mathrm{A} 1$ & $\mathrm{~A} 2$ & A3 & A4 & $\mathrm{B} 1$ & $\mathrm{~B} 2$ & B3 & B4 & $\mathrm{C} 1$ & $\mathrm{C} 2$ & $\mathrm{C} 3$ & $\mathrm{C} 4$ \\
\hline \multirow{3}{*}{$\begin{array}{l}\text { Input } \\
\text { data }\end{array}$} & \multirow{3}{*}{\multicolumn{2}{|c|}{$\begin{array}{l}\text { Cement paste }(\%) \\
\text { Air }(\%) \\
\text { Aggregate }(\%)\end{array}$}} & 29.08 & 27.84 & 26.98 & 25.78 & 29.08 & 27.83 & 26.98 & 25.78 & 29.02 & 27.79 & 26.95 & 25.73 \\
\hline & & & 2.01 & 4.01 & 6.01 & 8.01 & 2.01 & 4.02 & 6.01 & 8.01 & 2.05 & 4.06 & 6.04 & 8.05 \\
\hline & & & 68.91 & 68.15 & 67.01 & 66.21 & 68.91 & 68.15 & 67.01 & 66.21 & 68.93 & 68.15 & 67.01 & 66.22 \\
\hline \multirow{7}{*}{$\begin{array}{l}\text { Output } \\
\text { data }\end{array}$} & \multirow{5}{*}{$\begin{array}{l}\text { Standard } \\
\text { parameters }\end{array}$} & $N$ & 363 & 529 & 602 & 677 & 179 & 328 & 467 & 620 & 143 & 280 & 391 & 529 \\
\hline & & $A(\%)$ & 1.78 & 3.00 & 3.66 & 4.59 & 1.72 & 3.74 & 5.27 & 6.99 & 2.15 & 4.08 & 5.52 & 7.27 \\
\hline & & $A_{300}(\%)$ & 0.99 & 1.72 & 2.21 & 2.53 & 0.58 & 1.16 & 1.40 & 2.06 & 0.25 & 0.44 & 0.53 & 0.74 \\
\hline & & $\alpha\left(\mathrm{mm}^{-1}\right)$ & 35.86 & 30.97 & 28.88 & 25.90 & 18.25 & 15.40 & 15.55 & 15.55 & 11.67 & 12.05 & 12.42 & 12.77 \\
\hline & & $L(\mathrm{~mm})$ & 0.220 & 0.198 & 0.191 & 0.189 & 0.438 & 0.361 & 0.301 & 0.237 & 0.621 & 0.443 & 0.369 & 0.277 \\
\hline & \multicolumn{2}{|l|}{$\overline{P P V(\%)}$} & 77.40 & 94.36 & 98.42 & 99.50 & 22.94 & 41.70 & 56.53 & 68.15 & 17.74 & 33.24 & 46.55 & 57.75 \\
\hline & \multicolumn{2}{|l|}{$S(\%)$} & 97.5 & 99 & 100 & 100 & 80 & 96 & 100 & 100 & 92 & 98 & 100 & 100 \\
\hline
\end{tabular}

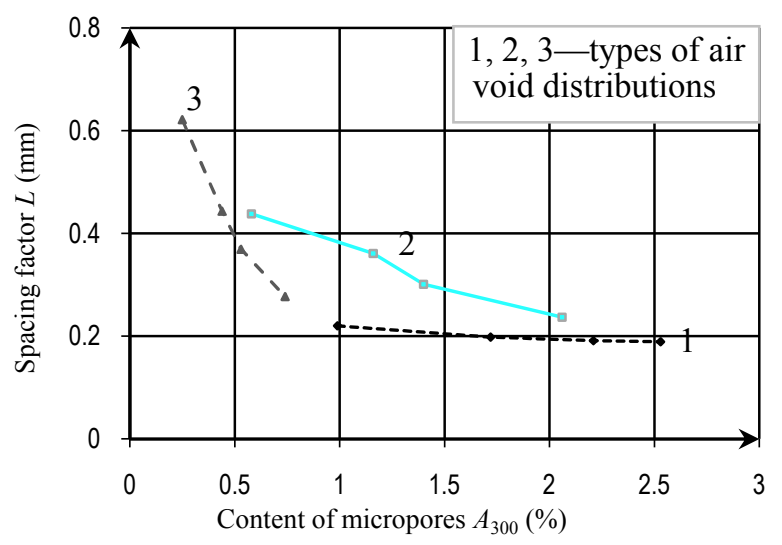

Fig. 8 The relationship between the standard spacing factor $L$ and the content of micropores $A_{300}$.

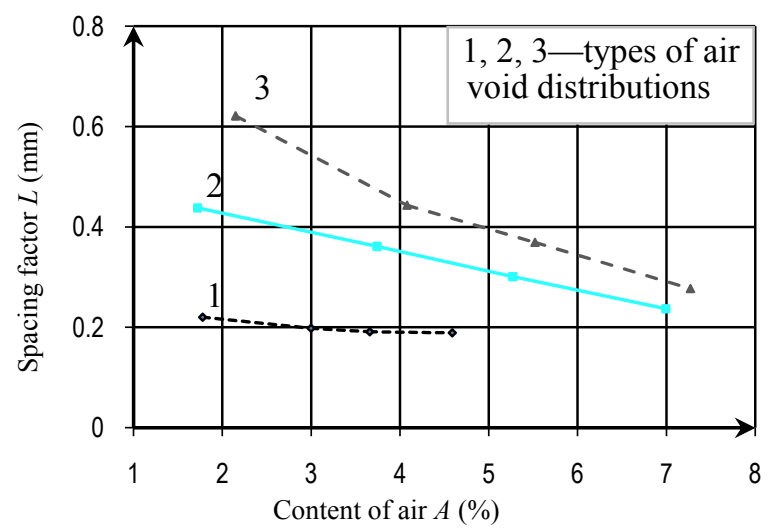

Fig. 9 The relationship between the standard spacing factor $L$ and the total air content $A$.

Air content introduced into the program differs from that calculated on the basis of the standard. Along with a decrease in the air content, it is easier to collocate it in the paste, and then during a linear analysis, more of air voids intersect with the measurement line. Increased amount of voids causes their clustering in the paste and then a lot of them are located between the measurement lines. Differences between the input and output $A$ are the largest for the highest content of air.

These data show that not the total air content but especially its structure has a huge impact on determined parameters. Generally, it is believed that the basic parameter that relates the quality of air-entrained concrete to its freeze-thaw resistance is spacing factor $L$. Concretes with $L$ smaller than $0.200 \mathrm{~mm}$ are considered to be frost resistant. As it is apparent from Fig. 8, the increase of $A_{300}$ micropores (smaller than $300 \mu \mathrm{m}$ ) causes that the spacing factor $L$ is reduced. Using the distribution of air voids with a larger percentage share of small pores (1st type of air-void distributions from Fig. 6), it is easy to achieve the standard spacing factor $L$ at $0.200 \mathrm{~mm}$.

Along with the decline in the share of the smallest voids in the total air content (2nd and 3rd types of air-void distributions from Fig. 6, respectively), the task becomes more difficult. The total air content must be increased to achieve the standard spacing factor (Fig. 9).

It is concluded that the distribution of air voids have a crucial impact on the pore structure parameters determined with all the three methods. With the increase of the air content, the problems with its location in paste increase. The deployment of voids is also affected by the presence of aggregate that is shown 
in Fig. 10. In the cement paste (dark grey), there are regions of greater or lesser concentration of the aggregate (black). Where there are a lot of aggregate particles, it is difficult to put in air voids (light grey). Additionally, the increase in the air content causes the air bubbles group together in the cement paste. From this point of view, the model reflects well enough the actual structure of air-entrained concrete. Examination of the aggregate-paste-air system gives better quality compared to other methods, where only the paste-air system is taken into account.

Essential differences are observed by comparing the relationship between the $P P V$ and $L$ (Fig. 11), and between the $P P V$ and $S^{*}$ (Fig. 12).

The worse the air-pore structure (smaller proportion of fine pores), the greater the difference between $P P V$ and $S^{*}$ is. The difference between $L, P P V$ and $S^{*}$ is the smallest for the variant of the concrete model with the best distribution of air voids (1st type of air-void distributions from Fig. 6). Even with the smallest air content, the standard spacing factor $L$ is $0.220 \mathrm{~mm}$, the percentage of protected paste by Philleo's method $\left(S^{*}\right)$ is $97.5 \%$, while $P P V$ is the smallest $(77.40 \%)$. The biggest difference between $P P V, L$ and $S^{*}$ is for the variant of the model with the distribution of air voids with the smallest percentage share of micropores (2nd and 3rd types of air-void distributions from Fig. 6, respectively). With the smallest content of air, the difference is the greatest, because the standard spacing factor is $0.621 \mathrm{~mm}, S^{*}$ equals $92 \%$, and the $P P V$ indicates that only less than $18 \%$ of the paste is protected by the air voids. For variants of models with the lowest content of the air, the obtained results for $P P V, S^{*}$, and $L$ are the most divergent. With the increase of $A_{300}$, micropores content and the total air content, the convergence increases. In each case, the ratio $P P V$ is lower than $S^{*}$, and at the standard spacing factor $L$, which is considered critical for obtaining frost resistance $(L \leq 0.200 \mathrm{~mm})$, does not reach $100 \%$ at all. This means that not all the cement paste volume is protected by air voids.

The discrepancies in the results for the analyzed three methods indicate that the approach based on the impact of aggregate and pore distribution is more accurate in comparison with other approaches. We believe that a better description of the pore structure parameters will allow more precise linking them to the frost resistance of concrete.

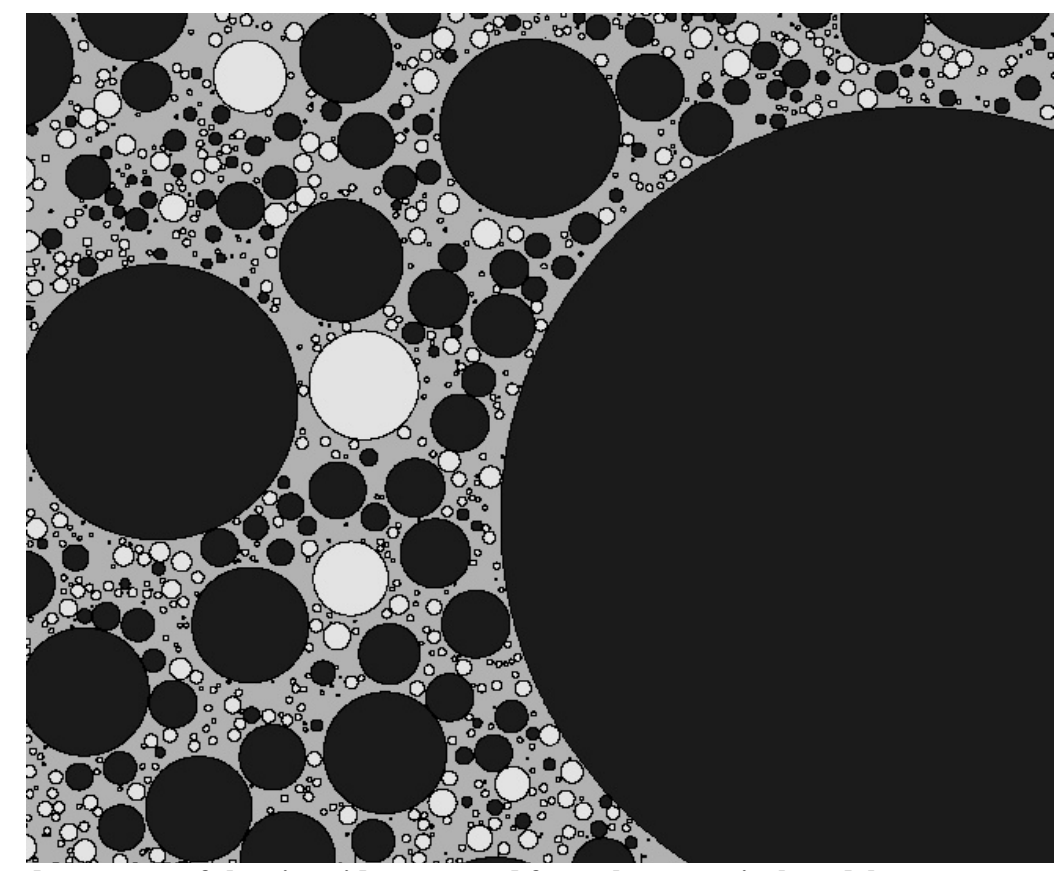

Fig. 10 The complicated structure of the air voids generated from the numerical model. 


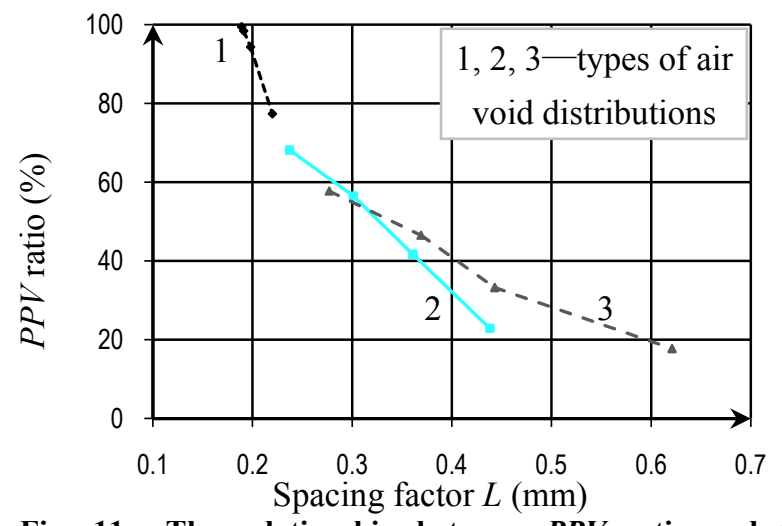

Fig. 11 The relationship between $P P V$ ratio and the standard spacing factor $L$.

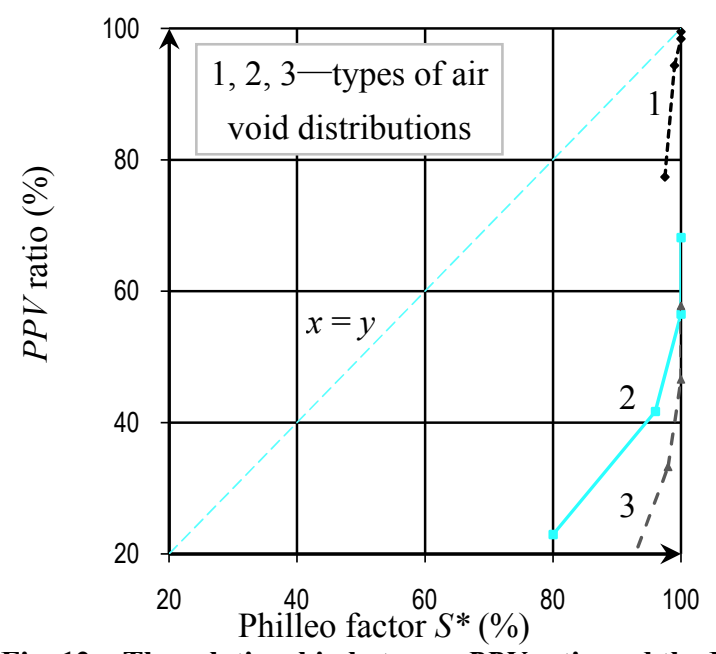

Fig. 12 The relationship between $P P V$ ratio and the Philleo factor $S^{*}$.

\section{Conclusions}

The standard approach, based on the Powers model, raises a number of doubts and concerns with respect to both methods of determining the pore structure parameters, and also of the congruence of thus obtained results with freeze-thaw resistance measurements.

In this paper, a method of determining the volume of protected paste on the basis of images generated from the numerical model of concrete grain structure including aggregate-paste-air system is proposed. It is a development of the concept put forward by Philleo. The model enables us to generate images that differentiate four basic concrete phases. The data entered into the program include the percentage content of aggregate, air and paste, the aggregate grading curve, air pore diameter distribution and the thickness of the surrounding $S$. The model is simple, but its development and improvement, taking into account more complex shapes of the aggregate, will have a more accurate reflection of the actual structure of the concrete.

The investigations presented in the study show that taking into account the aggregate-paste-air system produces results that are substantially different from those obtained for the paste-air system. On the basis of presented analyses, it can be concluded that, generally, the value of $P P V$ index clearly deviates from the values of the parameter proposed by Philleo. We believe that the 2D analysis of the porosity structure in air-entrained concretes proposed in the study will make it possible to describe more accurately the dependencies holding in the system and to obtain a better correlation between the parameters and freeze-thaw resistance results. These issues are to be verified in the future.

Application of this methodology to assess the quality of the actual structure of the concrete requires solving problems related to the differentiation of individual phases in real section samples by coloring and contrasting them, so that it will be possible to determine the $P P V$ index in real concrete section. For this purpose, the study will be continued.

\section{References}

[1] Polish Standards Committee. 2003. PN-EN 206-1:2003-1. Wymagania, Wtaściwości, produkcja i Zgodność (Specification, Performance, Production and Conformity). Polish Standards Committee. (in Polish)

[2] Road and Bridge Research Institute. 2010. Wymagania Techniczne dla Betonowych Nawierzchni Drogowych, Etap III (Technical Requirements for Concrete Pavements, Stage III). Warszawa: Road and Bridge Institute. (in Polish)

[3] Powers, T. C. 1949. "Air Requirement of Frost Resistant Concrete." In Proceedings of Highway Research Board, 184-202.

[4] Wawrzeńczyk, J., and Molendowska, A. 2011. "Use of Microspheres as an Alternative Method of Concrete Air-Entrainment." Budownictwo Technologie 
Architektura (Structure Technology Architecture) 4: 51-5. (in Polish)

[5] Springenschmidt, R., Breitenbücher, R., and Setzer, M. J. 1987. "Air-Entrained Concrete-Recent Investigations on the Fine Sand Composition. Waiting Time before Compaction and Redosing of Air-Entraining Agents." Betonwerk+Fertigteil-Technik 11: 742-8.

[6] Snyder, K. A. 1998. "A Numerical Test of Air Void Spacing Equations." Advanced Cement Based Materials 8: 28-44.

[7] Polish Standards Committee. 2008. PN-EN 480-11 Determination of the Characteristics of air Pores in Hardened Concrete. Warszawa: Polish Standards Committee. (in Polish)

[8] ASTM (American Society for Testing Materials). 1990. ASTM C 457, Standard Test Method for Microscopical Determination of Parameters of the Air Void System in Hardened Concrete. ASTM.

[9] Pigeon, M., and Pleau, R. 1995. Durability of Concrete in Cold Climates. London: E\&FN SPON,

[10] Philleo, R. E. 1983. "A Method for Analyzing Void Distribution in Air-Entrained Concrete." Cement, Concrete and Aggregates 2: 128-30.

[11] Attiogbe, E. K. 1997. "Volume Fraction of Protected Paste and Mean Spacing of Air Voids." ACI (American Concrete Institute) Materials Journal 94-M66: 588-91.

[12] Jin, S., Zhang, J., and Huang, B. 2013. "Fractal Analysis of Effect of Air Void on Freeze-Thaw Resistance of
Concrete." Construction and Building Materials 47: 126-30.

[13] Elsen, J., Lens, N., Vyncke, J., Aarre, T., Quenard, D., and Smolej, V. 1994. "Quality Assurance and Quality Control of Air Entrained Concrete." Cement and Concrete Research 24 (7): 1267-76.

[14] Jin, S., Zhang, J., and Huang, B. 2013. "Fractal Analysis of Effect of Air Void on Freeze-Thaw Resistance of Concrete." Construction and Building Materials 47: 126-30.

[15] Zalocha, D., and Kasperkiewicz, J. 2005. "Estimation of the Structure of Air Entrained Concrete Using a Flatbed Scanner." Cement and Concrete Research 35: 2041-6.

[16] MathWorks. 2004. MATLAB 7.0.1. MathWorks,

[17] Sadouki, H., and Van Mier, J. G. M. 1997. "Meso-Level Analysis of Moisture Flow in Cement Composites Using a Lattice-Type Approach." Materials and Structures 30: 579-87.

[18] Zheng, J. J., and Li, C. Q. 2002. "Three-Dimensional Aggregate Density in Concrete with Wall Effect." ACI Materials Journal 99: 568-75.

[19] Mohamed, A. R., and Hanse, W. 1999. "Micromechanical Modeling of Concrete Response under Static Loading-Part1: Model Development and Validation." ACI Materials Journal 96: 196-203.

[20] Wawrzeńczyk, J., Kozak, W., and Kłak, A. 2014. "Possibility of Pore Structure Distribution Application to the Description of Air-Entrained Concrete Porosity Structure." Structure and Environment 1: 5-12. 